\title{
Combinational Effect of Rumex tingitanus (Polygonaceae) Hexane Extract and Bacillus thuringiensis $\delta$-Endotoxin against Spodoptera littoralis (Lepidoptera: Noctuidae)
}

\author{
Dhekra Mhalla, ${ }^{1}$ Dalel Ben Farhat-Touzri, ${ }^{1}$ Slim Tounsi $\mathbb{D}^{1},{ }^{1}$ and Mohamed Trigui $\mathbb{D}^{1,2}$ \\ ${ }^{1}$ Laboratory of Biopesticides, Center of Biotechnology of Sfax, University of Sfax, P.O. Box 1177, 3018 Sfax, Tunisia \\ ${ }^{2}$ Research Unit "Coastal and Urban Environments" University of Sfax, Sfax Preparatory Engineering Institute, \\ BP 1172, 3018 Sfax, Tunisia \\ Correspondence should be addressed to Mohamed Trigui; mohamed.trigui@ipeis.rnu.tn
}

Received 10 April 2018; Revised 27 June 2018; Accepted 24 July 2018; Published 8 August 2018

Academic Editor: Roberto Amerigo Papini

Copyright (C) 2018 Dhekra Mhalla et al. This is an open access article distributed under the Creative Commons Attribution License, which permits unrestricted use, distribution, and reproduction in any medium, provided the original work is properly cited.

\begin{abstract}
The increasing insect resistance against Bacillus thuringiensis delta-endotoxins is a serious problem which makes it urgent to look for new eco-friendly strategies. Combining these toxins with other biomolecules is one of the promising strategies against insect pests. In this work, we evaluated the bioinsecticidal potential of Rumex tingitanus extracts and B. thuringiensis strain BLB250 against Spodoptera littoralis (Lepidoptera: Noctuidae) larvae. The chemical composition of the hexane extract, the most active fraction, was analyzed to validate the correlation between chemical composition and biological activity. Among the tested extracts, only the hexanic extract showed toxicity against first and second instar larvae with $\mathrm{LC}_{50}$ of 2.56 and $2.95 \mathrm{mg} \mathrm{g}^{-1}$, respectively. The Bacillus thuringiensis BLB250 delta-endotoxins showed toxicity with an $\mathrm{LC}_{50}$ of $56.3 \mu \mathrm{g} \mathrm{g}^{-1}$. Therefore, the investigated combinational effect of BLB250 delta-endotoxins and $R$. tingitanus hexane extract proved significant synergistic effect against $S$. littoralis larvae. The GC-MS analysis of $R$. tingitanus hexane extract showed the richness of this extract in phytosterols such as $\beta$ and $\gamma$-sitosterol (48.91\%), campesterol (6.43\%), and $\beta$-amyrin (8.92\%) which are known for their insecticidal activity. This novel finding highlights the potential use of this combination against insect pests to prevent the appearance of resistance problems.
\end{abstract}

\section{Introduction}

Spodoptera littoralis (Boisduval) (Lepidoptera: Noctuidae) is one of the most serious pests which are known for their high polyphagia, voracity, rapid development, and worldwide spread. It can attack 87 species of economically important plants including cotton, tomatoes, legumes, cruciferous, artichokes, strawberries, forage, corn, peppers, and other crops in Africa, Asia, and Europe $[1,2]$. Synthetic insecticides are extensively used to control this pest worldwide. However, their indiscriminate application has led to the development of insect resistance, environmental pollution, residual toxicity, and serious threats to the nontarget organisms including predators, pollinators, fish, and human beings [3]. According to the current European guidelines for agri- and horticulture, a combination of botanical pesticides and beneficial organisms is one of the potentially desirable alternatives in the integrated pest management. Plant extracts or metabolites and microbial formulations provide an interesting alternative to the conventional chemical insecticides. These biopesticides may be a promising part of insect biocontrol technology in the future [4]. Bacillus thuringiensis endotoxins (BLB250 endotoxins) are the most widely used microbial insecticides in the world [5]. They are toxic against different species of insect pests such as lepidoptera, diptera, and coleoptera. Many preparations based on $B$. thuringiensis have significant biochemical and physiological effects on $S$. littoralis larvae. However, developing resistance to this entomopathogenic bacterium requires finding out new methods for pest control [6]. On the other hand, more than 2000 plant species are known for their insecticidal activities because they are a rich source of secondary bioactive metabolites [7]. Plant extracts or metabolites are considered one of the most important control methods which are less hazardous to nontarget 
organisms, environmentally safe, and biodegradable [4]. The insecticidal potential of various plants against $S$. littoralis has been demonstrated by many researchers [4, 8, 9]. In this work, we evaluated the bioinsecticidal potential of Rumex tingitanus extracts and B. thuringiensis strain BLB250 against $S$. littoralis larvae. The chemical composition of the hexane extract, which is the most active fraction, was analyzed to prove the correlation between chemical composition and biological activity.

\section{Materials and Methods}

2.1. Plant Material. R. tingitanus leaves were harvested in March of 2015 from Sfax Tunisia (latitude $34^{\circ} 46^{\prime} 31^{\prime \prime} \mathrm{N}$ and longitude $10^{\circ} 45^{\prime} 59^{\prime \prime} \mathrm{E}$ ). The leaves were dried and stored in the Laboratory of Biopesticides and a voucher specimen was deposited in the Center of Biotechnology of Sfax, Tunisia.

2.2. Bacterial Strain. B. thuringiensis strain BLB250 used in this study was isolated in the Laboratory of Biopesticides from soil. The biochemical and molecular characterization as well as the produced delta-endotoxins have been previously studied by Benfarhat-Touzri et al. (2016) [10].

2.3. Insect. S. littoralis larvae used in these bioassays were reared on an artificial diet in the Laboratory of Biopesticides and maintained under standard conditions at $23^{\circ} \mathrm{C}, 65 \%$ relative humidity, and 16:8 h light:dark photoperiod. They fed on an artificial semisolid diet, consisting of a mixture of wheat germ, beer yeast, maize semolina, nipagine, ascorbic acid, wessan salt, sorbic acid, benzoic acid, agar, and water [11]. The diet was poured into sterile Petri dishes, allowed to cool thoroughly, and then stored at $4^{\circ} \mathrm{C}$ for up to 7 days. The adults were fed by a $10 \%$ sucrose solution.

2.4. Preparation of Plant Extracts. Fresh leaves of Rumex tingitanus were dried and fine powdered. The obtained powder $(1 \mathrm{~kg})$ was macerated with aqueous ethanol $(4 \mathrm{~L}$ of ethanol/water, $4: 1, \mathrm{v} / \mathrm{v}$ ) by occasional shaking at room temperature. After $48 \mathrm{~h}$, the extract was filtered and concentrated under vacuum. The resulting hydroalcoholic extract (RtEtOH- $\mathrm{H}_{2} \mathrm{O} ; 203 \mathrm{~g}$ ) was solubilized in water and fractionated with $\mathrm{n}$-hexane and then by ethyl acetate to obtain a nhexane fraction (RtHexF), ethyl acetate fraction (RtEtOAcF), and water fraction (RtWF), respectively [12].

2.5. GC-MS Analysis of $R$. tingitanus Hexane Extract. The quantitative analysis of $R$. tingitanus hexane extract was established by GC-MSHP model 6980 inert MSD (Agilent Technologies, USA), equipped with a mass selective detector (MSD5973, ionization voltage $70 \mathrm{eV}$; Agilent, Santa Clara, CA) and capillary column HP-5MS (30 m length, $0.25 \mathrm{~mm}$ diameter, and $0.25 \mathrm{~mm}$ film thickness). Helium was used as a carrier gas at a flow rate of $1 \mathrm{ml} \mathrm{min}^{-1}$. The sample was injected with a split mode $1 / 100$. The temperature of the injector was maintained at $280^{\circ} \mathrm{C}$. The original oven temperature was set to $50^{\circ} \mathrm{C}$ for $2 \mathrm{~min}$ and ramped to $300^{\circ} \mathrm{C}$ at a rate of $5^{\circ} \mathrm{C} \mathrm{min}^{-1}$ and then this temperature was held for $8 \mathrm{~min}$. The components were identified by careful examination of fragmentation patterns and spectral data obtained from the Wiley Registry of Mass Spectral Data 7th edition (Agilent Technologies, Inc.) and the National Institute of Standards and Technology 05 MS (NIST) library data. This determination was carried out in duplicate.

\subsection{Preparation of B. thuringiensis BLB250 Delta-Endotoxins.} $B$. thuringiensis strain BLB250 was grown on T3 solid culture medium for $72 \mathrm{~h}$ at $30^{\circ} \mathrm{C}$ [10]. The spore-crystal mixture collected in $1 \mathrm{M} \mathrm{NaCl}$ cold solution was harvested by centrifugation for $10 \mathrm{~min}$ at $10,000 \times \mathrm{g}$ and washed twice with cold distilled water. $50 \mu \mathrm{L}$ of spore-crystal mixtures were further solubilized in $50 \mathrm{mM} \mathrm{NaOH}$ and incubated during $2 \mathrm{~h}$ at $30^{\circ} \mathrm{C}$ [13]. BLB250 delta-endotoxin concentrations were determined by Bradford method [14].

\subsection{Bioinsecticidal Assays}

2.7.1. Chronic Toxicity. The chronic toxicity of $R$. tingitanus extracts (RtEtOH- $\mathrm{H}_{2} \mathrm{O}$, RtEtOAcF, RtHexF, and RtWF) and $B$. thuringiensis delta-endotoxins against $S$. littoralis larvae were examined according to the protocol described by Benfarhat-Touzri et al. [13], with slight modifications. Five concentrations of each tested extract $\left(0.3125-5 \mathrm{mg} \mathrm{g}^{-1}\right)$ and BLB250 delta-endotoxin (10-100 $\left.\mu \mathrm{g} \mathrm{g}^{-1}\right)$ were prepared separately to determine the fifty and ninety percent lethal concentrations $\left(\mathrm{LC}_{50}\right.$ and $\left.\mathrm{LC}_{90}\right)$ values. One gram of artificial diet was placed in a sterile Petri dish and blended with $100 \mu \mathrm{L}$ of the appropriate concentration of extracts and deltaendotoxin. After complete drying, ten insects of the newly molted first, second, third, and fourth instar larvae of $S$. littoralis were added to the mixture. Then, the plates were incubated for 48 hours under standard conditions at $23^{\circ} \mathrm{C}$, $65 \%$ relative humidity, and 16:8 h light:dark photoperiod. The untreated control groups were prepared in the same experimental conditions but the diet was impregnated with $50 \%$ of ethanol or buffer solution free of BLB250 deltaendotoxin. Each treatment was performed in triplicate. The larval mortality was determined within 48 hours. LC $_{50}$ and $\mathrm{LC}_{90}$ values were calculated by probit analysis.

2.7.2. Growth Inhibition. In order to assess the efficiency of $R$. tingitanus on larval growth, the artificial diet containing hexane extract in 5 concentrations $(0.3125,0.625,1.25,2.5$, and $5 \mathrm{mg} \mathrm{g}^{-1}$ ) was used. The plates were prepared as described above. Then, the newly molted fourth instar larvae of $S$. littoralis were placed individually in sterile Petri dishes. After incubation in the growth room (16:8 h light:dark, $\left.23^{\circ} \mathrm{C}\right)$, the larvae were weighed after 48 hours. The result was expressed as growth inhibition percentage (\%) using the following formula:

$$
\text { Growth inhibition }(\%)=100-\left[\left(\frac{T}{C}\right) \times 100\right]
$$

$\mathrm{T}$ is the sample larval weight and $\mathrm{C}$ is the control larval weight. Ten larvae were tested for each concentration. Three repetitions were performed for each treatment [15]. 
TABLE 1: Chemical composition of hexane extract prepared from $R$. tingitanus leaves.

\begin{tabular}{|c|c|c|c|}
\hline Compound & $\mathrm{Rt}(\min )^{\mathrm{a}}$ & $\mathrm{KI}^{\mathbf{b}}$ & Peak area $(\%)^{\mathrm{c}}$ \\
\hline Camphor & 9,754 & 1146 & 0.68 \\
\hline 6.10.14-Trimethyl-2-pentadecanone & 26.429 & 1847 & 0.40 \\
\hline Palmitate Methyl & 28.049 & 1928 & 0.15 \\
\hline Palmitate Ethyl & 29.360 & 1996 & 1.96 \\
\hline 9.12-Octadecadienoic acid Methyl & 31.214 & 2093 & 0.14 \\
\hline 9.12.15-Octadecatrienoic acid Ethyl & 31.335 & 2113 & 0.25 \\
\hline Trans-phytol & 31.606 & 2117 & 0.90 \\
\hline 9.12-Octadecadienoic acid Methyl & 32.412 & 2155 & 1.21 \\
\hline 9.12.15-Octadecatrienoic acid Ethyl & 32.540 & 2215 & 1.85 \\
\hline \multicolumn{4}{|l|}{ Phytosterols } \\
\hline$\delta$-5-Ergosterol & 39.67 & 3029 & 0.56 \\
\hline Campesterol & 42.359 & 3131 & 6.43 \\
\hline Stigmasterol & 44.687 & 3170 & 1.17 \\
\hline$\beta$-Sitosterol & 45.463 & 3187 & 22.59 \\
\hline$\beta$-amyrin & 46.375 & 3337 & 8.92 \\
\hline$\gamma$-Sitosterol & 47.068 & 3351 & 26.32 \\
\hline Stigmasta-3.5-dien-7-one & 48.176 & 3432 & 1.49 \\
\hline$\sum$ Identified compounds & & & 75.02 \\
\hline
\end{tabular}

${ }^{\mathrm{a}}$ Rt: retention time.

${ }^{\mathrm{b}} \mathrm{KI}$ : Kovats indices on HP-5MS capillary column with reference to $\mathrm{C}_{10}-\mathrm{C}_{22} \mathrm{n}$-alkanes injected in the same conditions.

${ }^{c_{\%}} \%$ : percentages are the means of two runs and were obtained from electronic integration measurements using a selective mass detector.

2.7.3. Joint Effect Studies. The $R$. tingitanus hexane extract (RtHexF) at concentrations of $0.3125,0.625,1.25,2.5$, and $5 \mathrm{mg}$ $\mathrm{g}^{-1}$ and BLB250 delta-endotoxins $\left(30 \mu \mathrm{g} \mathrm{g}^{-1}\right)$ were blended together in binary combinations. For each tested mixture, three repetitions were performed. The toxicity experiments were carried out as described for chronic toxicity where larval mortalities were determined after 48 hours and the actual mortalities were compared to the expected mortalities based on the following formula:

$$
\mathrm{E}=\mathrm{O}_{\mathrm{a}}+\mathrm{O}_{\mathrm{b}}\left(1-\frac{\mathrm{O}_{\mathrm{a}}}{100}\right)
$$

$\mathrm{E}$ is expected mortality and $\mathrm{O}_{\mathrm{a}}$ is the observed mortality of BLB250 and $\mathrm{O}_{b}$ is the observed mortality of RtHexF at the given concentration.

The Chi-squared test $\chi^{2}$ was used to designate the effects of each mixture which can be additive, antagonistic, or synergistic.

$$
\chi^{2}=\frac{\left(\mathrm{O}_{\mathrm{m}}-\mathrm{E}\right)^{2}}{\mathrm{E}}
$$

$\mathrm{E}$ is the expected mortality from the binary combination and $\mathrm{O}_{\mathrm{m}}$ is the observed mortality; $\chi^{2}$ with $\mathrm{df}=1$ and $\mathrm{p}=0.05$ is 3.84 .

This test differentiates the results into three categories. A pair with $\chi^{2}$ values $<3.84$ indicates an additive effect, with $\chi^{2}$ values $>3.84$ and $\mathrm{O}_{\mathrm{m}}>\mathrm{E}$ indicates a synergistic effect, whereas a pair with $\chi^{2}$ values $>3.84$ and $\mathrm{O}_{\mathrm{m}}<\mathrm{E}$ indicates an antagonistic effect [8].

\section{Results}

3.1. Chemical Analysis of $R$. tingitanus Hexane Extract. Analysis of RtHexF by GC-MS method revealed a complex mixture of chemical families consisting essentially of phytosterol (67.48\%) and fatty acid compounds $(3.6 \%)$ (Table 1). Four major compounds $(>6 \%)$ were identified as $\gamma$ sitosterol (26.32\%), $\beta$-sitosterol (22.59\%), $\beta$-amyrin (8.92\%), and campesterol $(6.43 \%)$ followed by fatty acids (palmitic and linolenic acids), stigmasta-3,5-dien-7-one (1.49\%), $\delta$-5Ergosterol (0.52\%), and Camphor (0.68\%).

\subsection{Insecticidal Potential of R. tingitanus against S. littoralis}

3.2.1. Toxicity. Chronic toxicity of $R$. tingitanus extracts, measured as mortality within 48 hours, was determined by oral application to 1 st, $2 \mathrm{nd}, 3 \mathrm{rd}$, and 4 th instar larvae of S. littoralis. The results displayed in Table 2 indicated that among the tested extracts, only the hexane extract (RtHexF) exhibited remarkable larvicidal activity. The larval mortalities were increased with the rise of the extract concentration. After a forty-eight-hour treatment, the highest concentration $\left(5 \mathrm{mg} \mathrm{g}^{-1}\right)$ caused $70 \pm 0.8 \%, 60 \pm 2.4 \%$, and $10 \pm 0.0 \%$ of mortality against 1st, 2nd, and 3rd instar larvae of S. littoralis, respectively. However, the exposure of larvae to the other three extracts did not cause any mortality. No mortality was observed against 4 th instar larvae, either. No toxicity was produced from the negative control over the $48 \mathrm{~h}$.

Based on the comparison of the lethal concentrations, the chronic toxicity of RtHexF against 1st instar larvae was slightly higher $\left(\mathrm{LC}_{50}=2.56 \mathrm{mg} \mathrm{g}^{-1} ; \mathrm{LC}_{90}=6.02 \mathrm{mg} \mathrm{g}^{-1}\right)$ than 
TABLE 2: Chronic toxicity of $R$. tingitanus extracts against $S$. littoralis larvae within $48 \mathrm{~h}$.

\begin{tabular}{|c|c|c|c|c|c|}
\hline \multirow{2}{*}{ Treatment } & \multirow{2}{*}{ Concentration $\left(\mathrm{mg} \mathrm{g}^{-1}\right)$} & \multicolumn{4}{|c|}{ Mortality (\%) } \\
\hline & & 1st instar & 2nd instar & 3rd instar & 4th instar \\
\hline \multirow{2}{*}{ RtEtOH- $\mathrm{H}_{2} \mathrm{O}$} & 2.5 & 0 & 0 & 0 & 0 \\
\hline & 5 & 0 & 0 & 0 & 0 \\
\hline \multirow{2}{*}{ RtEtOAcF } & 2.5 & 0 & 0 & 0 & 0 \\
\hline & 5 & 0 & 0 & 0 & 0 \\
\hline \multirow{5}{*}{ RtHexF } & 0.3125 & $10 \pm 1.0$ & 0 & 0 & 0 \\
\hline & 0.625 & $23.3 \pm 1.1$ & $15 \pm 0.2$ & 0 & 0 \\
\hline & 1.25 & $30 \pm 0.5$ & $25 \pm 1.0$ & 0 & 0 \\
\hline & 2.5 & $50 \pm 0.5$ & $50 \pm 1.0$ & 0 & 0 \\
\hline & 5 & $70 \pm 0.8$ & $60 \pm 2.4$ & $10 \pm 0.0$ & 0 \\
\hline \multirow{2}{*}{ RtWF } & 2.5 & 0 & 0 & 0 & 0 \\
\hline & 5 & 0 & 0 & 0 & 0 \\
\hline Negative control & - & 0 & 0 & 0 & 0 \\
\hline
\end{tabular}

Average mortality in \% obtained after application of $R$. tingitanus extracts: Rt EtOH- $\mathrm{H}_{2} \mathrm{O}$; hydroalcoholic extract, RtHexF; n-hexane fraction, RtEtOAcF; ethyl acetate fraction and RtWF; water fraction mixed with $1 \mathrm{~g}$ of artificial semisolid diet cubes. Larval mortality against the 1st to 4th instar larvae was determined after 2 days.

TABLE 3: Lethal concentrations $\left(\mathrm{LC}_{50}\right.$ and $\left.\mathrm{LC}_{90}\right)$ of $R$. tingitanus hexane extract $\left(\mathrm{mg} \mathrm{g}^{-1}\right)$ and $B$. thuringiensis delta-endotoxin BLB250 $\left(\mu \mathrm{g} \mathrm{g}^{-1}\right)$ against $S$. littoralis larvae.

\begin{tabular}{lcc}
\hline Instar larvae & $\mathbf{L C}_{\mathbf{5 0}}\left(\mathrm{mg} \mathrm{g}^{-\mathbf{1}}\right)$ & $\mathbf{L C}_{\mathbf{9 0}}\left(\mathrm{mg} \mathrm{g}^{-\mathbf{1}}\right)$ \\
\hline RtHexF & & \\
1st instar & $2.56 \pm 0.56$ & $6.02 \pm 1.41$ \\
2nd instar & $2.95 \pm 0.65$ & $6.65 \pm 1.73$ \\
BLB250 & $\mathbf{L C}_{50}\left(\boldsymbol{\mu \mathrm { g } \mathrm { g } ^ { - 1 } )}\right.$ & $\mathbf{L C}_{\mathbf{9 0}}\left(\boldsymbol{\mu \mathrm { g } \mathrm { g } ^ { - 1 }}\right)$ \\
2nd instar & $56.3 \pm 5.83$ & - \\
\hline
\end{tabular}

the toxicity against 2 nd instar larvae $\left(\mathrm{LC}_{50}=2.95 \mathrm{mg} \mathrm{g}^{-1}\right.$; $\mathrm{LC}_{90}=6.65 \mathrm{mg} \mathrm{g}^{-1}$ ). For the $3 \mathrm{rd}$ instar larvae, the lethal concentrations could not be determined because the highest applied concentration caused a lower mortality rate than $50 \%$ (Table 3).

3.2.2. Growth Inhibition. A significant growth inhibition was observed in 4th instar larvae of S. littoralis after the oral application of $R$. tingitanus hexane extract (Figure 1). 70\% inhibition rate was obtained after exposing of $5 \mathrm{mg} \mathrm{g}^{-1}$ hexane extract.

3.3. Insecticidal Potential of B. thuringiensis BLB250 against S. littoralis. The chronic toxicity of BLB250 delta-endotoxins was investigated by oral application to second instar $S$. littoralis larvae. The BLB250 delta-endotoxins exhibited a high insecticidal activity with $\mathrm{LC}_{50}$ of $56.3 \pm 5.83 \mu \mathrm{g} \mathrm{g}^{-1}$. No activity was determined for the control over the test period (Table 3).

3.4. Synergistic Effect of $R$. tingitanus Hexane Extract and $B$. thuringiensis Delta-Endotoxin. In order to improve toxicity and decrease the $S$. littoralis resistance to $B$. thuringiensis

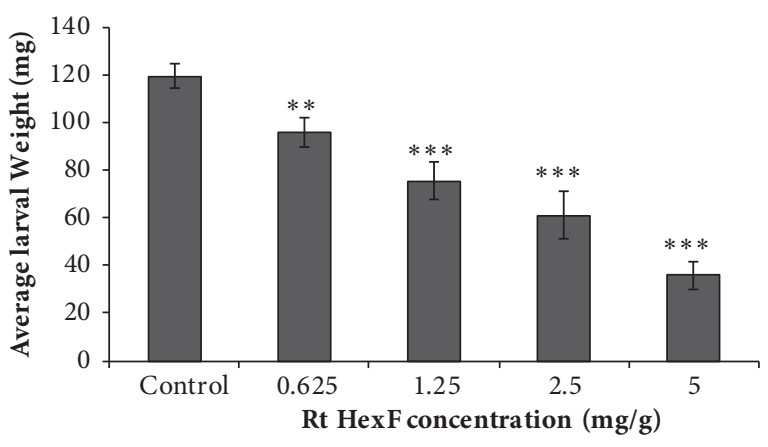

FIGURE 1: Growth inhibitory action of $R$. tingitanus hexane extract on Spodoptera littoralis after 48 hours of feeding on a treated diet. Ten fourth instar larvae of $S$. littoralis were exposed to different concentrations of Rt hexane extract and larvae mass was recorded at $48 \mathrm{~h}$. Each treatment was replicated three times. Error bars represent the standard deviation of three replications. Superscripts $* *$ and $* *$ * denote statically significant at $P<0.01, P<0.001$ with comparison to control.

toxins, we have combined BLB250 delta-endotoxins (30 $\mu \mathrm{g}$ $\mathrm{g}^{-1}$ ) with $R$. tingitanus hexane extract at concentrations of $0.3125,0.625,1.25,2.5$, and $5 \mathrm{mg} \mathrm{g}^{-1}$ against 1st instar larvae and $0.625,1.25,2.5$, and $5 \mathrm{mg} \mathrm{g}^{-1}$ against 2 nd instar larvae. In total, 9 binary combinations were tested against 1st and 2nd instar larvae of $S$. littoralis. As shown in Table 4, the results analysis indicated that an addition of a fixed deltaendotoxin concentration to the increasing concentrations of hexane extract improved the lethal effect. All the tested binary mixtures showed synergistic effects either against 1st and 2 nd instar larvae of $S$. littoralis except that of the lowest concentrations. The highest $\chi^{2}$ value (10.9) was recorded for the BLB250 and RtHexF combination at $5 \mathrm{mg} \mathrm{g}^{-1}$. 


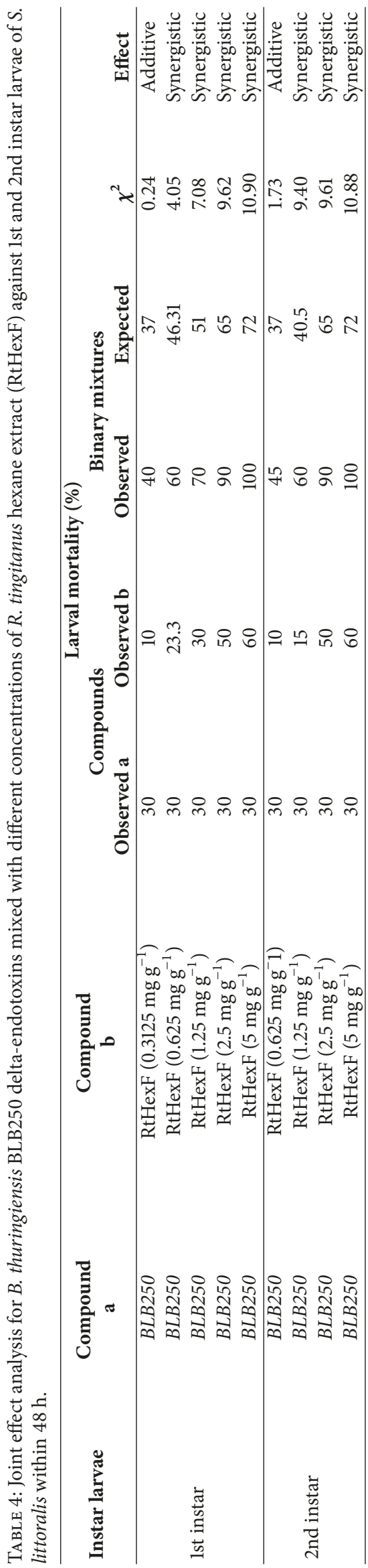




\section{Discussion}

Chemical insecticides are extensively used against a broad range of bioaggressors such as insects, fungi, bacteria, and viruses. However, their adverse toxicological effects and the resistance developed by pests have urged a continuous search for safer methods [4]. Currently, the plant extracts are considered as a potential source of bioactive compounds which are potentially useful against diverse groups of insect pests [8].

The present study emphasized, for the first time, the promising insecticidal activities of $R$. tingitanus hexane extract against lepidopteran larvae. The mode of action of this insecticide varies according to the larval stage. It is a larvicide against 1 st and 2 nd instar larvae $\left(\mathrm{LC}_{50}=2.56 \mathrm{mg} \mathrm{g}^{-1} ; \mathrm{LC}_{50}\right.$ $=2.95 \mathrm{mg} \mathrm{g}^{-1}$, respectively) and an antifeedant against 4 th instar larvae. The larvacidal properties of $R$. tingitanus hexane extract to $S$. littoralis could be attributed to the presence of high percentage of compounds which are known for their potential insecticidal effect, particularly $\beta$ and $\gamma$-Sitosterol and $\beta$-amyrin. In fact, Saeidnia et al. [16] reported the larvicidal activity of $\beta$-sitosterol. It was demonstrated that $\beta$ Sitosterol showed insecticidal, antifeeding, and insect growth regulatory activities against Spodoptera littoralis larvae [17]. Kannan et al. [18] showed that $\beta$-amyrin has antifeedant and growth regulating activities against Spodoptera litura (Lepidoptera: Noctuidae). In addition, minor compounds of the RtHexF, such as Stigmasta-3,5-dien-7-one and camphor, have also reported for their potential insecticidal activity $[19,20]$. The tests carried out on the Spodoptera frugiperda larvae revealed the potential insecticidal activity of Castela coccinea including Stigmasta-3,5-dien-7-one [21]. Pavela et al. [8] proved the effectiveness of camphor against S. littoralis. Therefore, the diversity of major and minor compounds presents in the plant extract and the synergy between them should be taken into account for their insecticidal activity. From these results, the $R$. tingitanus hexane extract could be used for the biological control of $S$. littoralis larvae. Furthermore, lepidopteran pests control using $B$. thuringiensis toxins is currently preferred because they exhibit no threat to the environment and human health [22]. In this work, we have demonstrated the effectiveness of $B$. thuringiensis BLB250 delta-endotoxins against $S$. littoralis with impressive $\mathrm{LC}_{50}$ of $56.3 \pm 5.83 \mu \mathrm{g} \mathrm{g}^{-1}$. In order to improve the lethal effect and prevent the development of certain resistance cases, the combinational effect between $R$. tingitanus hexane extract and $B$. thuringiensis delta-endotoxins was investigated. The analysis of the results revealed the dominance of synergistic effects of mixing these two natural biomolecules, against 1st as well as 2 nd instar larvae of $S$. littoralis. This combination may cause an as high as $100 \%$ efficacy in terms of toxicity for lepidopteran larvae compared to the control. Thus, our findings in this context may be considered as an outstanding way of biological pest management. The high cost of microbial toxin productions could be considerably lowered by using lower quantities of bacterial toxin mixed with plant extracts which approximately doubles the larvicidal effect. In fact, adding a lower amount of BLB250 delta-endotoxins $\left(30 \mu \mathrm{g} \mathrm{g}^{-1}<\mathrm{LC}_{50}\right)$ improved the toxicity of $R$. tingitanus hexane extract and vice versa. However, the assessment of the mode of action of the combinational effect of BLB250 delta-endotoxins and the plant extract against $S$. littoralis larvae may be a complex process which deserves further investigation. The synergism could be explained by inhibiting the $S$. littoralis larvae capacity to use detoxifying enzymes and the disruption of the integrity of the gut due to delta-endotoxins fixation on the midgut epithelial cell at specific receptors leading to the insect starvation and death $[4,23]$. Therefore, the combinational effect or synergism between plant extracts and microbial or insecticide control agents cause more aggressive and a longer-lasting effects. The identification of these botanical components within mixtures has the potential to develop more effective and more economical biopesticides [24]. In fact, this joint-action may be an ideal solution to prevent the appearance of certain resistance cases caused by the systemic and repeated application of synthetic insecticide or B. thuringiensis delta-endotoxins [4].

\section{Conclusion}

In summary, it can be noted that compounds contained in $R$. tingitanus hexane extract could be a new alternative to chemical insecticides and could be used in the development of new natural insecticides. Mixing this extract with $B$. thuringiensis delta-endotoxins might be an ideal solution to delay or attenuate the insect resistance to $B$. thuringiensis toxins. These combinations may be integrated into an insecticidal formulation active against some Lepidoptera larvae. However, further tests need to be performed to investigate the mode of action and cost-efficacy of these combinations in greenhouses and fields.

\section{Data Availability}

No data were used to support this study.

\section{Conflicts of Interest}

The authors have declared that there are no conflicts of interest.

\section{Acknowledgments}

This work was supported by grants from the Tunisian "Ministry of Higher Education, Scientific Research". The authors would like to thank the English Professor Teacher Pr. Abdelmajid Dammak for proofreading the paper.

\section{References}

[1] M. M. Sadek, "Antifeedant and toxic activity of Adhatoda vasica leaf extract against Spodoptera littoralis (Lep., Noctuidae)," Journal of Applied Entomology, vol. 127, no. 7, pp. 396-404, 2003.

[2] A. F. El-Aswad, S. A. M. Abdelgaleil, and M. Nakatani, "Feeding deterrent and growth inhibitory properties of limonoids from Khaya senegalensis against the cotton leafworm, Spodoptera littoralis," Pest Management Science, vol. 60, no. 2, pp. 199-203, 2004 . 
[3] F. Tonial, B. H. L. N. S. Maia, A. M. Sobottka et al., "Biological activity of Diaporthe terebinthifolii extracts against Phyllosticta citricarpa," FEMS Microbiology Letters, vol. 364, no. 5, Article ID fnx026, 2017.

[4] S. A. Mansour, M. S. Foda, and A. R. Aly, "Mosquitocidal activity of two Bacillus bacterial endotoxins combined with plant oils and conventional insecticides," Industrial Crops and Products, vol. 35, no. 1, pp. 44-52, 2012.

[5] D. BenFarhat-Touzri, M. Saadaoui, L. Abdelkefi-Mesrati, I. Saadaoui, H. Azzouz, and S. Tounsi, "Histopathological effects and determination of the putative receptor of Bacillus thuringiensis CrylDa toxin in Spodoptera littoralis midgut," Journal of Invertebrate Pathology, vol. 112, no. 2, pp. 142-145, 2013.

[6] F. Özkan Ç., A. Sevim, Z. Demirbağ, and I. Demir, "Investigating internal bacteria of Spodoptera littoralis (Boisd.) (Lepidoptera: Noctuidae) larvae and some Bacillus strains as biocontrol agents," Turkish Journal of Agriculture and Forestry, vol. 38, no. 1, pp. 99-110, 2014.

[7] D. Haouas, M. Ben Halima-Kamel, F. Skhiri-Harzallah, and M. Ben Hamouda, "Chrysanthemum methanolic extracts as potential insecticidal sources on tribolium confusum du val (Coleoptera: Tenebrionidae)," Journal of Agronomy and Crop Science, vol. 7, no. 1, pp. 93-97, 2008.

[8] R. Pavela, "Acute, synergistic and antagonistic effects of some aromatic compounds on the Spodoptera littoralis Boisd. (Lep., Noctuidae) larvae," Industrial Crops and Products, vol. 60, pp. 247-258, 2014.

[9] M. Méndez, A. Custodio, and M. Provencio, "New molecular targeted therapies for advanced non-small-cell lung cancer," Journal of Thoracic Disease, vol. 3, no. 1, pp. 30-56, 2011.

[10] D. Benfarhat-Touzri, F. Driss, and S. Tounsi, "A promising HD133-like strain of Bacillus thuringiensis with dual efficiency to the two Lepidopteran pests: spodoptera littoralis (Noctuidae) and Ephestia kuehniella (Pyralidae)," Toxicon, vol. 118, pp. 112120, 2016.

[11] S. Poitout, R. Bues, and C. L. Rumeur, "Elevage de plusieurs espèces de lépidoptères noctuidae sur milieu artificiel riche et sur milieu artificiel simplifié," Annales de Zoologie Ecologie Animale, vol. 2, pp. 79-91, 1970.

[12] D. Mhalla, A. Bouaziz, K. Ennouri et al., "Antimicrobial activity and bioguided fractionation of Rumex tingitanus extracts for meat preservation," Meat Science, vol. 125, pp. 22-29, 2017.

[13] D. Benfarhat-Touzri, A. B. Amira, S. B. khedher, A. Givaudan, S. Jaoua, and S. Tounsi, "Combinatorial effect of Bacillus thuringiensis kurstaki and Photorhabdus luminescens against Spodoptera littoralis (Lepidoptera: Noctuidae)," Journal of Basic Microbiology, vol. 54, no. 11, pp. 1160-1165, 2014.

[14] M. M. Bradford, "Rapid and sensitive method for the quantitation of microgram quantities of protein utilizing the principle of protein-dye binding," Analytical Biochemistry, vol. 72, no. 1-2, pp. 248-254, 1976.

[15] M. Topiar, M. Sajfrtova, R. Pavela, and Z. Machalova, "Comparison of fractionation techniques of $\mathrm{CO}_{2}$ extracts from Eucalyptus globulus-Composition and insecticidal activity," The Journal of Supercritical Fluids, vol. 97, pp. 202-210, 2015.

[16] S. Saeidnia, A. Manayi, A. R. Gohari, and M. Abdollahi, "The story of beta-sitosterol-a Review," European Journal of Medicinal Plants, vol. 4, no. 5, pp. 590-609, 2014.

[17] C. Bu, J. Li, X.-Q. Wang et al., "Transcriptome Analysis of the carmine spider mite, Tetranychus cinnabarinus (Boisduval,
1867) (Acari: Tetranychidae), and its response to $\beta$-sitosterol," BioMed Research International, vol. 2015, Article ID 794718, 12 pages, 2015.

[18] S. Kannan, B. Vijayakumar, C. Sureshkumar, R. Mohankumar, and S. Narasimhan, "Insect antifeedant and growth regulating activities of $\beta$-amyrin from Sarcostemma acidum," Asian Journal of Chemistry, vol. 25, no. 2, pp. 1167-1168, 2013.

[19] K. Polatoğlu, Ö. C. Karakoç, Y. Yücel Yücel et al., "Insecticidal activity of Salvia veneris Hedge. Essential oil against coleopteran stored product insects and Spodoptera exigua (Lepidoptera)," Industrial Crops and Products, vol. 97, pp. 93-100, 2017.

[20] S. Banerjee, S. Singha, S. Laskar, and G. Chandra, "Efficacy of Limonia acidissima L. (Rutaceae) leaf extract on larval immatures of Culex quinquefasciatus Say 1823," Asian Pacific Journal of Tropical Medicine, vol. 4, no. 9, pp. 711-716, 2011.

[21] M. L. Martínez, G. von Poser, A. Henriques, M. Gattuso, and C. Rossini, "Simaroubaceae and Picramniaceae as potential sources of botanical pesticides," Industrial Crops and Products, vol. 44, pp. 600-602, 2013.

[22] S. Ben Khedher, A. Kamoun, S. Jaoua, and N. Zouari, "Improvement of Bacillus thuringiensis bioinsecticide production by sporeless and sporulating strains using response surface methodology," New Biotechnology, vol. 28, no. 6, pp. 705-712, 2011.

[23] T. S. Thangam and K. Kathiresan, "Synergistic effects of insecticides with plant extracts on mosquito larvae," Tropical Biomedicine, vol. 7, pp. 135-137, 1990.

[24] E. A.-S. Shaalan, D. V. Canyon, M. W. F. Younes, H. AbdelWahab, and A.-H. Mansour, "Synergistic efficacy of botanical blends with and without synthetic insecticides against Aedes aegypti and Culex annulirostris mosquitoes," Journal of Vector Ecology, vol. 30, no. 2, pp. 284-288, 2005. 


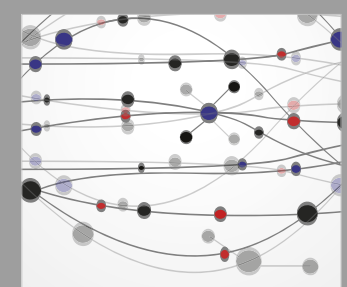

The Scientific World Journal
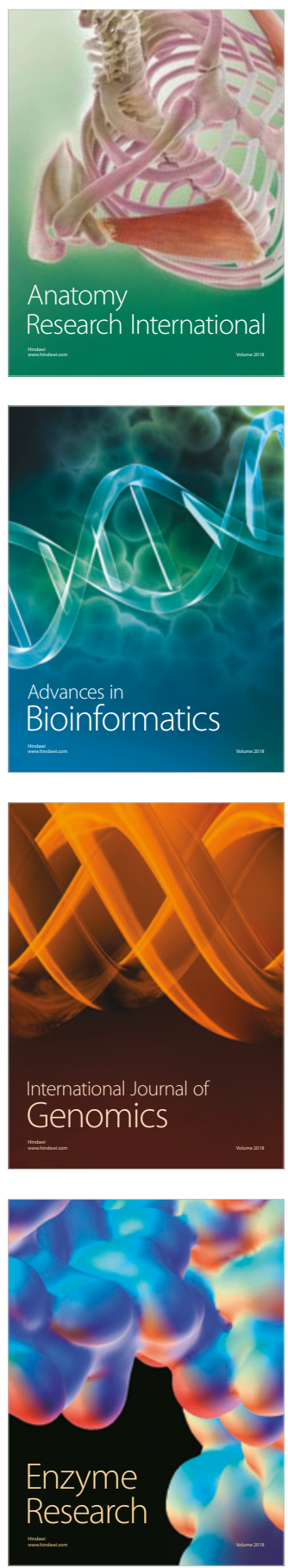
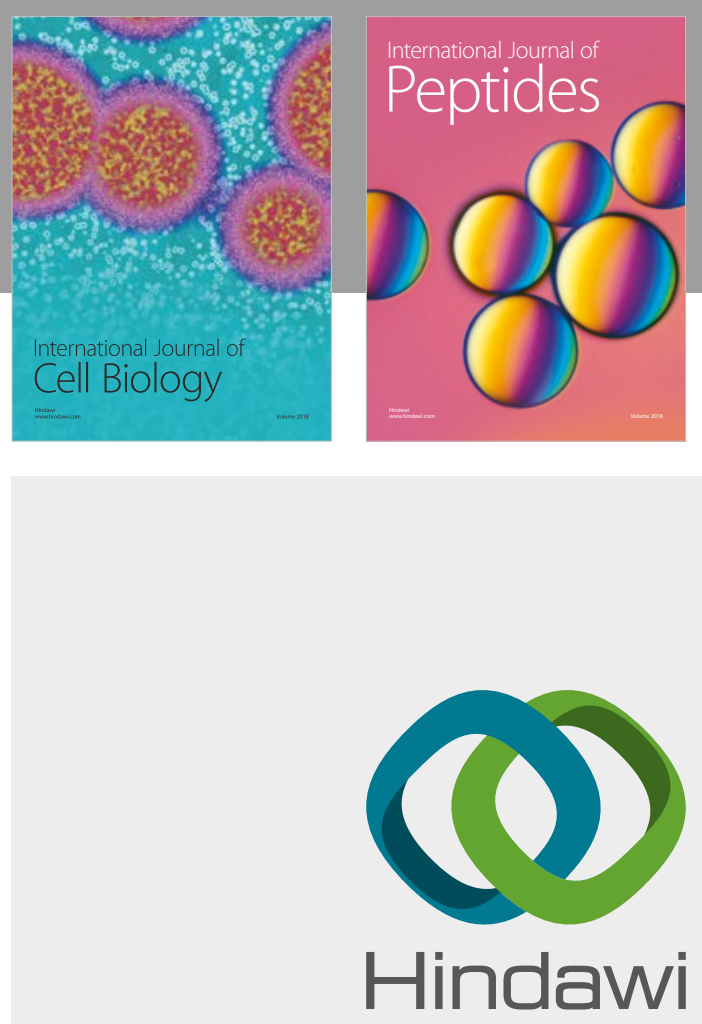

Submit your manuscripts at

www.hindawi.com
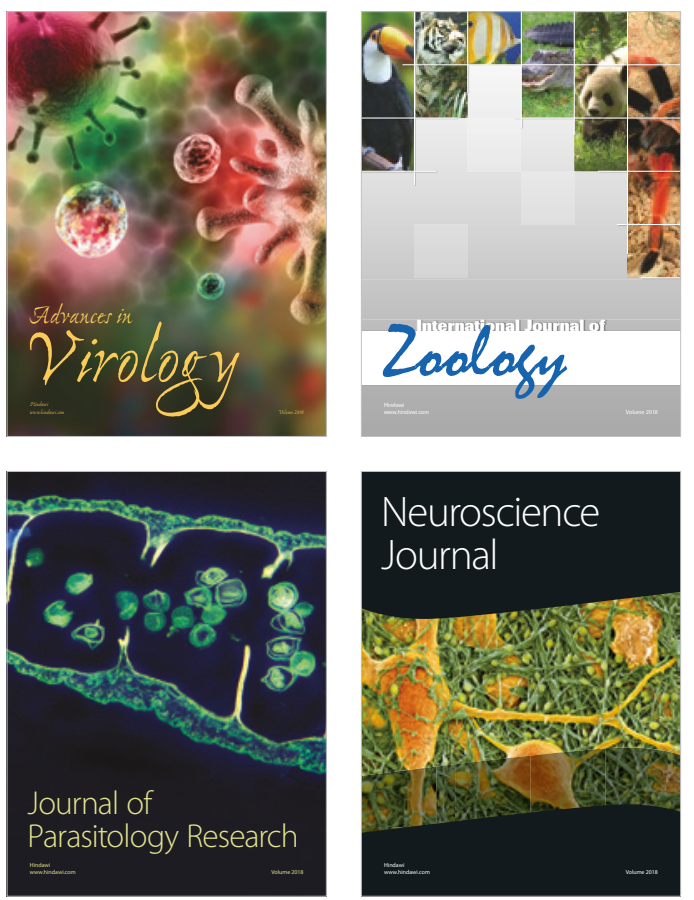
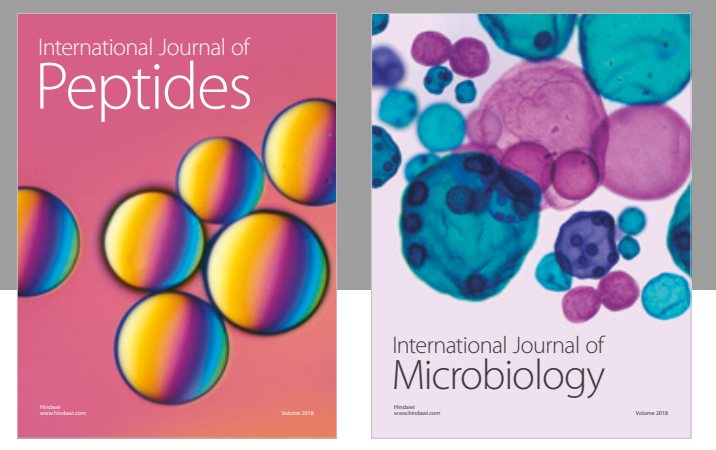

nternational Journal of Microbiology
Journal of
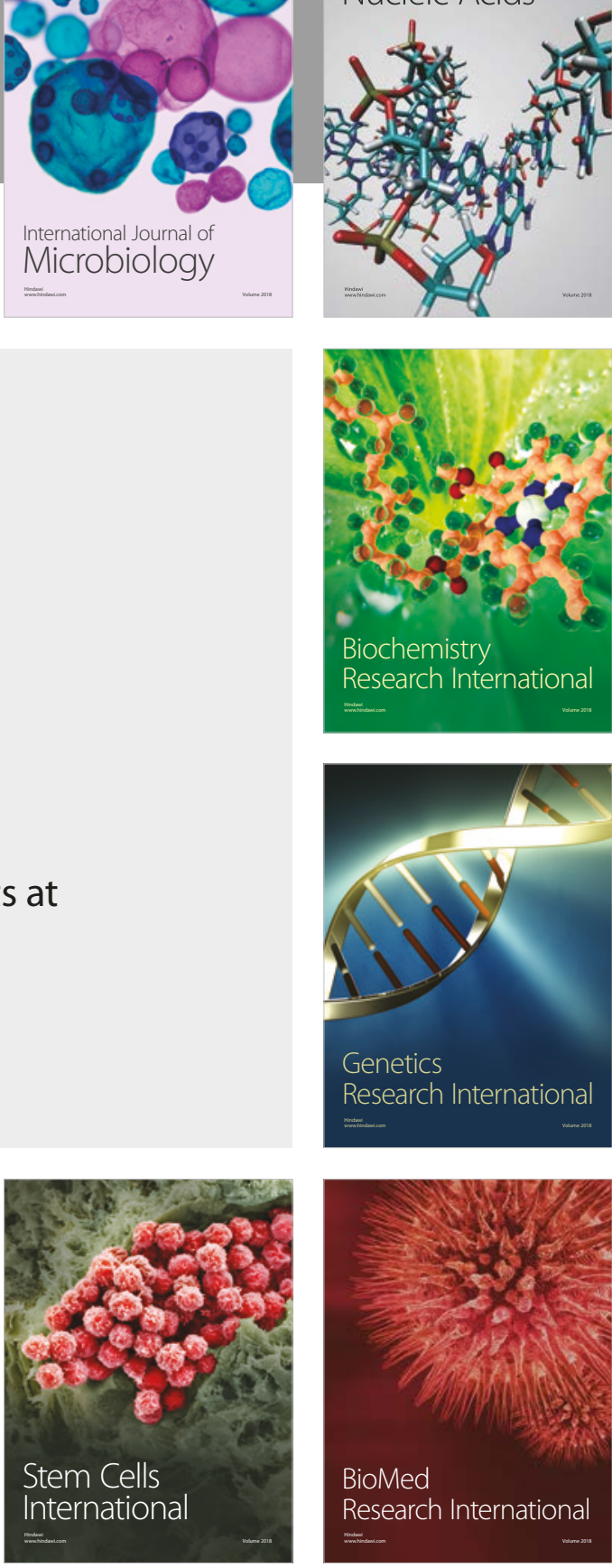
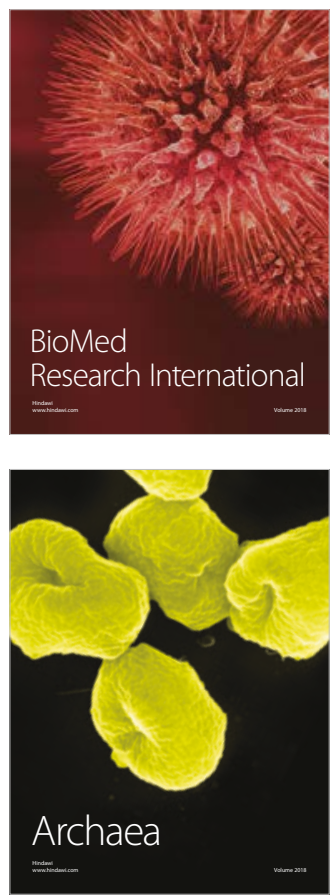